Mini review

\title{
Electrochemical Assay Methods for Protein Kinase Activity
}

\author{
Dezhan Tan ${ }^{1,2}$, Feng $\mathrm{Li}^{2}$ and Binbin Zhou ${ }^{3, *}$ \\ ${ }^{1}$ School of Mathematics and Statistics, Shangqiu Normal University, Shangqiu, Henan 476000, \\ People's Republic of China \\ ${ }^{2}$ Henan Key Laboratory of Biomolecular Recognition and Sensing, College of Chemistry and \\ Chemical Engineering, Shangqiu Normal University, Shangqiu, Henan 476000, People's Republic of \\ China \\ ${ }^{3}$ Hunan Institute of Food Quanlity Supervision Inspection and Research, Building B, No. 238, Ave. \\ Timesun, District Yuhua, Changsha, Hunan 410111, People's Republic of China \\ *E-mail: lifeng1985@tju.edu.cn (F. L.); bbzhou1985@163.com (B. Z.)
}

doi: $10.20964 / 2019.06 .75$

Received: 21 February 2019 / Accepted: 15 April 2019 / Published: 10 May 2019

Protein phosphorylation catalyzed by protein kinase is the most frequent post-translational modification, and plays a critical role in intracellular signal transduction pathways. Deregulation of kinase activity is a frequent cause of various human diseases, including cancers. Moreover, kinase is widely regarded as a family of extremely important molecular target for drug therapy. Therefore, sensitive and specific detection of protein kinase activity and inhibition is essential to the prerequisite and foundation for the study of fundamental biochemical processes, the clinical diagnosis and drug discovery. In recent years, tremendous advances have been achieved in electrochemical biosensors for protein kinase activity. This article reviews the recent developments in the designed strategies for electrochemical detection of kinase.

Keywords: Phosphorylation; kinase; electrochemistry; biosensors

\section{$\underline{\text { FULL TEXT }}$}

(C) 2019 The Authors. Published by ESG (www.electrochemsci.org). This article is an open access article distributed under the terms and conditions of the Creative Commons Attribution license (http://creativecommons.org/licenses/by/4.0/). 